\title{
"The Ethics of Sustainability" - A Debatable Outline for the Security of Man and Nature
}

\author{
Rabin Das ${ }^{1}$, Ramu Guchhait ${ }^{2}$ \\ Assistant Professor of Geography \& Guest Lecturer of Geography, Bajkul Milani Mahavidyalaya (V.U.)
}

\begin{abstract}
The issue is about what we regard as ethically acceptable in terms of the distribution of well-being, sacrifice and risks between rich and poor, the present and future and humans and non-humans.The ethical framework of economic contractarinism and utilitarianism may be unable to cope with the concerns of sustainability, but what should be put in its place? The first would be the most extensive basic equity/liberties for each person consistent with a similar liberty for each others (Equity within generation). There should be no social and economic inequalities like authority and wealth. The fundamental problem of utilitarianism is that it does not take seriously the distinction between individuals but it takes the choice for one person to maximize happiness. Second would be the equity between generations (inter-generation equity). Each generation would save the resources in order to enable to next generation to enjoy better life, because they care about their descendents. Each generation would benefited by previous accumulated capital and resources. Third would be an alternative approach to sustainability pioneered by John Pezzy is appealing to genetically based motivations. Human beings generally show a great deal of concern for their children's future but they don't care about anybody else's children. The nature of the situation means that individuals concern about their children is not enough, sustainability is a public good which requires public polices to influence behaviour. The next will be principle concept of environmentalism. We should care about our environment at any stage of decision making in case of socio-economic concerns. Liberalism and socialism what would be the way of sustainability? That is not big concern but it should be remembered that every decision should made by look after as well as the environmental concern and also the concern about the need of future generation. At last, it would be said that ethics for sustainability to be spoken and remembered but not in actual work as it is popularized in paper and pen. Then it would say to all of them that man can change and nature can't tolerate.
\end{abstract}

Keywords: economic contractarinism, utilitarianism, basic equity/liberties, sustainability, environmentalism, Liberalism and socialism

\section{Introduction}

Sustainable development is a common agenda for global concern, which everybody agrees upon, but bringing this global concern into public policies is a difficult task. Sustainability is an important concept that is widely referenced and that has achieved broad support. Yet it remains inherently difficult to implement because of its complexity and due to the enormous shifts in thinking that it proposes. Particularly challenging is the development and implementation of technology, the vast majority of which has significant potential negative consequences for the health of both people and planet. This paper provides natural and social scientists, engineers, architects, builders and other technical professionals with a clear description of the meaning of sustainability and a practical guide to the ethical challenges involved in its promotion and achievement. It describes the ethical concepts and principles that are inherent in sustainability and is designed to aid these professions in evaluating and directing their activities, particularly when developing, deploying, and employing technology. Sustainability is commonly understood to require the balanced pursuit of three goods: ecological health, social equity, and economic welfare. It is grounded on the ethical commitment to the well-being not only of contemporary populations but also the wellbeing and enhanced opportunities of future generations. The scientific and technical professions have a special responsibility in this regard because the knowledge and technologies they develop and employ have immense impacts on natural environments, economies, and the empowerment of citizens and societies. Moreover, their efforts and achievements can continue to produce effects, for good or ill, well into the future. In articulating the challenge of pursuing both intergenerational and intra-generational benefits for environments, societies and economies, this paper grounds practical decision making in ethical concepts and values. Through exposure to a wide variety of concrete examples, case studies, moral debates, and exercises, readers will gain a nuanced understanding of the ethics of sustainability and develop a set of practical decision skills that may be employed in its pursuit. The book engages a broad range of applications such as nuclear and solar energy systems, biotechnology and genetic engineering, materials extraction, design and production, built environment design and construction, information technology and robotics, nanotechnology and communications technology, agricultural and forestry technologies. While addressing large-scale national and global issues such as climate change, higher energy costs, water and food shortage, poverty, species extinction, and resource depletion, The Ethics of Sustainability also brings home the personal impact scientists and technical professionals can have at the workplace, in their communities, and in their homes.

\section{Objectives}

1) To establish the concern of risks and security.

2) To analyse the various ethical stand point of sustainability.

3) To analyse the challenges of sustainability

\section{Methodology}

We have maintained the intensive study of the different literature relating the subject matter to reach the objectives. The primary and secondary data and documents of different 


\section{International Journal of Science and Research (IJSR) \\ ISSN (Online): 2319-7064 \\ Index Copernicus Value (2013): 6.14 | Impact Factor (2015): 6.391}

world environmental conference and meetings have been considered and justified in self of this study.

\section{Literature Review}

Sustainable development has its roots in ideas about sustainable forest management which were developed in Europe during the seventeenth and eighteenth centuries. In response to a growing awareness of the depletion of timber resources in England, John Evelyn_argued that "sowing and planting of trees had to be regarded as a national duty of every landowner, in order to stop the destructive overexploitation of natural resources" in his 1662 essay Sylva. In 1713 Hans Carl von Carlowitz,a senior mining administrator in the service of Elector Frederick Augustus I of_Saxony published Sylvicultura economical, a 400-page work on forestry. Building upon the ideas of Evelyn and French minister Jean-Baptise Colbert, von Carlowitz developed the concept of managing forests for sustained yield. His work influenced others, including Alexander von Humboldt and Georg Ludwig Hartig, leading in turn to the development of a science of forestry. This in term influenced people like Gifford Pinchot, first head of the US Forest Service, whose approach to forest management was driven by the idea of wise use of resources, and Aldo Leopold whose land ethic was influential in the development of the environmental movement in the 1960s

Following the publication of Rachel Carson's Silent Spring in 1962, the developing environmental movement drew attention to the relationship between economic growth and development and environmental degradation. Kenneth E. Boulding in his influential 1966 essay The Economics of the Coming Spaceship Earth identified the need for the economic system to fit itself to the ecological system with its limited pools of resources. One of the first uses of the term sustainable in the contemporary sense was by the Club of Rome in 1972 in its classic report on the Limits to Growth, written by a group of scientists led by Dennis and Donella Meadows of the Massachusetts Institute of Technology. Describing the desirable "state of global equilibrium", the authors wrote: "We are searching for a model output that represents a world system that is sustainable without sudden and uncontrolled collapse and capable of satisfying the basic material requirements of its entire people."

In 1980 the International Union for the Conservation of Nature published a world conservation strategy that included one of the first references to sustainable development as a global priority. Two years later, the United Nations World Charter for Nature raised five principles of conservation by which human conduct affecting nature is to be guided and judged. In 1987 the United Nations World Commission on Environment and Development released the report Our Common Future, commonly called the Brundtland Report. The report included what is now one of the most widely recognized definitions of sustainable development.

Sustainable development is development that meets the needs of the present without compromising the ability of future generations to meet their own needs. It contains within it two key concepts:
The concept of 'needs', in particular, the essential needs of the world's poor, to which overriding priority should be given; and The idea of limitations imposed by the state of technology and social organization on the environment's ability to meet present and future needs.

- World Commission on Environment and Development, Our Common Future (1987)

In 1992, the UN Conference on Environment and Development published in 1992 the Earth Charter, which outlines the building of a just, sustainable, and peaceful global society in the $21^{\text {st }}$ century. The action plan Agenda 21 for sustainable development identified information, integration, and participation as key building blocks to help countries achieve development that recognizes these interdependent pillars. It emphasises that in sustainable development everyone is a user and provider of information. It stresses the need to change from old sector-cantered ways of doing business to new approaches that involve crosssectoral co-ordination and the integration of environmental and social concerns into all development processes. Furthermore, Agenda 21 emphasises that broad public participation in decision making is a fundamental prerequisite for achieving sustainable development. Under the principles of the United Nations Charter the Millennium Declaration identified principles and treaties on sustainable development, including economic development, social development and environmental protection. Broadly defined, sustainable development is a systems approach to growth and development and to manage natural, produced, and social capital for the welfare of their own and future generations. The term sustainable development as used by the United Nations incorporates both issues associated with land development and broader issues of human development such as education, public health, and standard of living. A 2013 study concluded that sustainability reporting should be reframed through the lens of four interconnected domains: ecology, economics, politics and culture.

\section{What is Ethics?}

Ethics is a branch of philosophy that seeks to define what is right and what is wrong on a universal basis. For example stealing, lying, cheating, killing and indifference to the wellbeing of others are considered to be unethical. Preserving human life, concern for others, honesty and truthfulness are considered to be ethical.

Deontological ethics emphasises on the relationship between duty and the morality of human actions. Deontology (Greek deon, "duty," and logos, "science") is therefore science of duty. In deontological ethics an action is considered morally good because of some characteristic of the action itself, not because the consequence of the action is good. It follows the concept that moral duty is to do good actions and not bad ones. This ethical model simply suggests adherence to independent moral rules or duties regardless of the consequences of such actions. When we follow our duty, we are behaving morally. When we fail to follow our duty, we are behaving immorally. The concept of Karma is close to the notion of deontological ethics. The concept of Karma means that a person should follow his or her duty without thinking of the rewards for his or her actions. Bhagavad Gita 


\section{International Journal of Science and Research (IJSR) \\ ISSN (Online): 2319-7064 \\ Index Copernicus Value (2013): 6.14 | Impact Factor (2015): 6.391}

teaches the following: - $\hbar$ at, without being attached to the fruits of activities, one should act as a matter of duty, for by working without attachment one attains the Supreme (Verse 19, Chapter 3).

Teleological Ethics (derived from the Greek word „telos meaning end, purpose) is an ethical theory that holds that the ends or consequences of an act determine whether an act is good or evil. Rightness of actions is determined solely by the good consequences. It is also known as consequential ethics.

\section{Common people and concept of ethics}

Some individuals consider it unethical and immoral to unnecessarily waste resources or to encourage the extinction of any species, as a result they have reduced their use and waste of resources. Others do not believe that there are any serious environmental or resource problems and thus do not consider resource waste as unethical or immortal. Indeed, they argue that maximizing their consumption is a moral act because it promotes the economic growth that is a source of jobs for the poor. Most people belief that nature exists only for our use, and our role is to conquer and subdue wild nature and matter and energy resources are unlimited so that these can be used for ever.

\section{Conceptual Focussing of Environmental Ethics}

Environmental Ethics (Ethics of Nature) is the area of applied ethics that discusses, reflects and reasons on normative measures (values, rules, norms, criteria) for dealing with non-human natural entities in a responsible way. According to Patrick Hegarty; "Environmental Ethics is concerned with ethical decisions and values covering the environment for the purpose of sustaining that environment verses personal gain. To what extent does man damage the environment for achievement of personal goals and compromise his ethics at the expense of the environment". According to Lesley Lam, Environmental Ethics regards the management of the land and natural resources based on factors such as culture, religion and experience. Environmental Ethics is the base of reasoning for, e.g., the following fields of action within society: environmental protection, animal protection, nature protection, animal rights, and sustainability issues. Accordingly, environmental ethics includes such questions as:

- Why care about nature for itself when only people matter?

- When species or landscapes or wilderness areas are destroyed, what, of value, is lost to mankind?

- Will future generations miss what we have „taken from them ${ }^{\text {e? }}$ ?

- Does land ownership make moral sense, or is it a morally absurd and repugnant concept in Western culture meant to deprive Indigenous peoples of their customary land?

- Do human beings have a need for nature that implies an obligation to preserve it?

Three main areas of environmental ethics

1)Resource Ethics: How do we legitimize the responsible management of scarce and deployable resources and environmental media (water, soil, air, climate, etc.)?
2)Animal Ethics: How do we legitimize the responsible treatment of animals, particularly those which can suffer from pain?

3)Ethics of Nature Protection (= Ethics of Nature): How do we legitimize the responsible treatment with ,collective biotic entities, for example: populations, species, and ecosystems?

However, a number of environmentalists advocate a sustainable-earth ethics such as:

1) Nature does not exist primarily for human use but for all living species.

2) Matter and energy sources are finite and must not be wasted.

3) Human beings are part of nature.

4) Development must be needed but without disturbing other needs to sustain.

5) Biological diversity is the world $^{\text {ee }} \mathrm{s}$ asset not for destructing them to individual use.

6) We the present world people are minor and upcoming future generation are major in case of needs of recourse.

\section{What is sustainable development?}

Ecologists implies sustainable development as a sustain production level that can be borne by the ecosystem whereas from literal meaning sustainable development interprets as sustained growth; sustained change, or simply successful development. According to other terminologists, this is the 'Eco-Development' used to indicate that development should be based upon an ECOnomic theory renewed by ECOlogical considerations. However, Sustainable development (SD) is a process for meeting human development goals while maintaining the ability of natural systems to continue to provide the natural resources and ecosystem services upon which the economy and society depend While the modern concept of sustainable development is derived most strongly from the 1987 Brundtland Report. The Brundtland Commissiones brief definition of sustainable development is as the "ability to make development sustainable to ensure that it meets the needs of the present without compromising the ability of future generations to meet their own needs". Sustainable development is the organizing principle for sustaining finite resources necessary to provide for the needs of future generations of life on the planet. It is a process that envisions a desirable future state for human societies in which living conditions and resource-use continue to meet human needs without undermining the "integrity, stability and beauty" of natural biotic systems. In the extensive discussion and use of the concept since then, there has generally been recognition of three aspects of sustainable development.

- Economic Perspective and Sustainability: An economically sustainable system must be able to produce goods and services on a continuing basis, to maintain manageable levels of government and external debt, and to avoid extreme sectoral imbalances which damage agricultural or industrial production. Economic sustainability is the ability of an economy to support a defined level of economic production indefinitely. Since the Great Recession of 2008 this is the world's biggest apparent problem, which endangers progress on the environmental sustainability problem. 
International Journal of Science and Research (IJSR)

ISSN (Online): 2319-7064

Index Copernicus Value (2013): 6.14 | Impact Factor (2015): 6.391

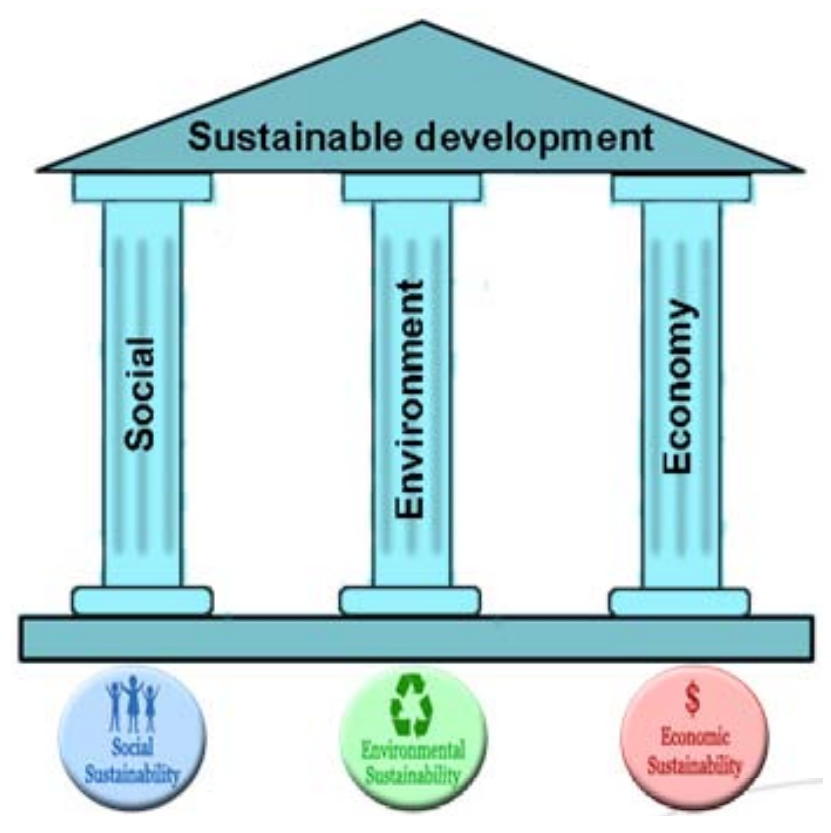

- Environmental Perspective and Sustainability: An environmentally sustainable system must maintain a stable resource base, avoiding over-exploitation of renewable resource systems or environmental sink functions, and depleting non-renewable resources only to the extent that investment is made in adequate substitutes. This includes maintenance of biodiversity, atmospheric stability, and other ecosystem functions not ordinarily classed as economic resources. Environmental sustainability is the ability of the environment to support a defined level of environmental quality and natural resource extraction rates indefinitely. This is the world's biggest actual problem, though since the consequences of not solving the problem now are delayed, the problem receives too low a priority to solve.

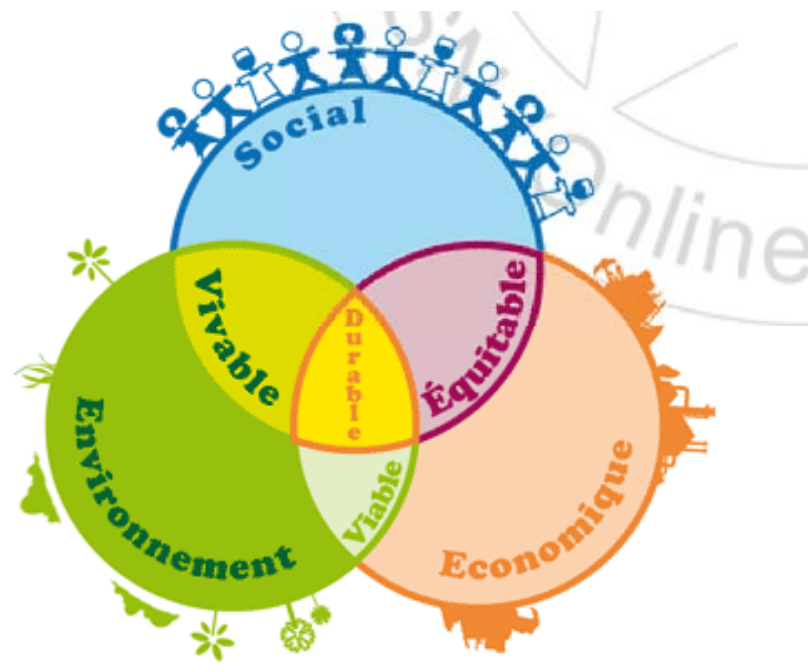

- Social Perspective and Sustainability: A socially sustainable system must achieve distributional equity, adequate provision of social services including health and education, gender equity, and political accountability and participation. Social sustainability is the ability of a social system, such as a country, family, or organization, to function at a defined level of social well being and harmony indefinitely. Problems like war, endemic poverty, widespread injustice, and low education rates are symptoms a system is socially unsustainable.

\section{Discussions}

\section{A. Establishing the concern of risks and security}

\section{(a) Population and Consumption:}

Much has been said about the role of population as the cause of many global problems due to the need to feed, clothe, and house Earth"s still rapidly growing human population. In fact the combination of population and per capita consumption is challenging the carrying capacity of the planet. In addition to the burden of a rapidly growing global population on relatively scarce food, water, land, and materials resources, the wealthier nations consume far more per capita than the poorer countries. The world"s wealthiest countries, with less than 20 percent of the world's population, contribute roughly 40 percent of global carbon emissions, and they are responsible for more than 60 percent of the total carbon dioxide that fossil fuel combustion has added to the atmosphere since the Industrial Revolution began. But this picture is now changing rapidly, particularly in China, where emissions are now raising at 10 percent a year, 10 times the average rate in industrial nations. By 2007 China's fossil fuel emissions exceeded those of the United States and continue to grow rapidly. Global population continues to grow at an alarming rate, with a population the size of Mexico"s (about 80 million) being added to the planet each year and almost 1 billion people per decade. Consumption is another side of the problem, especially per capita consumption of key natural resources which varies greatly around the world. Typically, the citizens of rich industrialized nations use more of the world's resources and produce more waste. As a result they sometimes deplete their own resources and often the resources of other countries. For many resources, the U.S. is the world's largest consumer in absolute terms and for others it is the largest per capita consumer. For 11 out of 20 major traded commodities, the U.S. is the greatest consumer. These include commodities such as corn, coffee, copper, lead, zinc, tin, aluminium, rubber, oil seeds, oil and natural gas.10 A typical example is meat. China, with the world's largest population, is the highest overall producer and consumer of meat, but the highest per-capita consumption in the world is that of the United States. The average United States citizen consumes more than three times the global average of 37 kilos per person per year. Africans consume less than half the global average, and South Asians consume the least, less than 6 kilos per person per year. Other resources are used much more variably, depending on local circumstances. Fish, for instance, has been a cheap source of protein for hundreds of millions of poor people wherever it has been available. The highest consumption levels are in some of the world's poorest states, such as the Maldives or Kiribati, where fish is plentiful. Per-capita consumption is also very high in rich nations with well-established fishing traditions -- 91 and 66 kilos per capita in Iceland and Japan respectively; way above the global average of 16 kilos per capita per year.11 To pursue sustainability, the so-called "twin horns of the dilemma," population and consumption, must both be addressed. 


\section{International Journal of Science and Research (IJSR) \\ ISSN (Online): 2319-7064 \\ Index Copernicus Value (2013): 6.14 | Impact Factor (2015): 6.391}

\section{(b) Climate Change:}

Changes in the Earth ${ }^{\text {ee }}$ s climate are the rule rather than the exception and there is ample evidence that over the past several million years there have been significant shifts in the Earth $^{\text {ee }}$ average annual temperature. As defined by the National Oceanographic and Atmospheric and Administration (NOAA), climate change consists of longterm fluctuations in temperature, precipitation, wind, and all other aspects of the Earth's climate. The United Nations Framework Convention on Climate Change describes the phenomenon as a change of climate attributable directly or indirectly to human activity that alters the composition of the global atmosphere, and that is, in addition to natural climate variability, observable over comparable time periods. The Intergovernmental Panel on Climate Change (IPCC) was established by the World Meteorological Organization (WMO) and the United Nations (UN) in 1988 to assess, on a comprehensive, objective, open, and transparent basis, the scientific, technical, and socioeconomic information relevant to understanding the scientific basis of risk of humaninduced climate change, its potential impacts, and options for adaptation and mitigation. The Fourth Assessment Report of the IPCC, published in 2007, concludes that the globally averaged surface temperatures have increased by $0.3 \pm 0.1^{\circ} \mathrm{F}$ $\left(0.6 \pm 0.2^{\circ} \mathrm{C}\right)$ over the twentieth century. For a range of scenarios, the globally averaged surface air temperature is projected by models to warm 0.8 to $3.2^{\circ} \mathrm{F}\left(1.4 \mathrm{o}\right.$ C to $\left.5.8^{\circ} \mathrm{C}\right)$ by 2100 relative to 1990 . Furthermore, globally averaged sea level is projected by models to rise 0.30 to 2.9 feet $(0.09$ to 0.88 meters) by 2100 . These projections indicate that the warming would vary by region and be accompanied by increases and decreases in precipitation.12 Moreover; there would be changes in climate variability, as well as in the frequency and intensity of some extreme climate phenomena. It is important to note that the behaviour of global systems such as climate is nonlinear. Each increase in carbon dioxide will not necessarily produce a proportional change in global temperature. However, the dynamic, chaotic character of the Earth "s climate is such that climate can suddenly "flip" from one temperature regime to another in a relatively short time. Indeed, fossil records indicate that previous flips have occurred, with temperature increasing or decreasing almost 10o $\mathrm{F}\left(5.6^{\circ} \mathrm{C}\right)$ in about a decade. The potential for climate change has profound implications for every aspect of human activity on the planet. Shifting temperatures, more violent storms, rising sea levels, melting glaciers, and other effects will displace people, affect food supplies, reduce biodiversity, and greatly reduce the quality of life.

\section{(c) Mineral Resource Depletion:}

The depletion of key resources needed to support the energy and materials requirements of today ${ }^{\text {ee }}$ s technological, developed world societies, is a threat to the high quality of life enjoyed by North Americans, Europeans, Japanese, and the other countries that make up these societies. Evidence todate seems to indicate that we have maximized our ability to extract oil and that we are in an era of probably far higher prices for oil-based products, among them gasoline, diesel, jet fuel, and oil-based polymers. A similar scenario is playing out with other key resources, most notably metals. A recent study of the supply and usage of copper, zinc and other metals has determined that supplies of these resources-even if recycled--may fail to meet the needs of the global population.13 Even the full extraction of metals from the Earth's crust and extensive recycling programs may not meet future demand if all countries try and attain the same standard of living enjoyed in developed nations. The researchers, Robert Gordon and Thomas Graedel, based their study on metal still in the Earth, in use by people and lost in landfills. Using copper stocks in North America as a starting point, they tracked the evolution of copper mining, use and loss during the 20th century. They then applied their findings and additional data to an estimate of global demand for copper and other metals if all nations were fully developed and used modern technologies. The study found that all of the copper in ore, plus all of the copper currently in use, would be required to bring the world to the level of the developed nations for power transmission, construction and other services and products that depend on copper. Globally, the researchers estimate that 26 percent of extractable copper in the Earth's crust is now lost in non-recycled wastes; while lost zinc is estimated at 19 percent. Interestingly, the researchers said that current prices do not reflect those losses because supplies are still large enough to meet demand, and new methods have helped mines produce material more efficiently. While copper and zinc are not at risk of depletion in the immediate future, the researchers believe scarce metals, such as platinum, are at risk of depletion in this century because there is no suitable substitute for their use in devices such as catalytic converters and hydrogen fuel cells. And because the rate of use for metals continues to rise, even the more plentiful metals may face similar depletion risks in the not too distant future. The impacts on metal prices due to a combination of demand and dwindling stocks have been dramatic. In a single year 2005-2006, zinc and copper experienced a $300 \%$ rise, and metals such as nickel, brass and stainless steel rose by about $250 \%$. The good news is the there is a renewed emphasis on recycling, using only the exact quantity of metals required, and insuring that all implant scrap is recovered during manufacturing.

\section{(d) Loss of Biodiversity:}

Biodiversity refers to the number and variety of living organisms and the ecosystems in which they occur. The concept of biodiversity encompasses the number of different organisms, their relative frequencies, and their organization at many levels, ranging from complete ecosystems to the biochemical structures that form the molecular basis of heredity. Thus, biodiversity expresses the range of life on the planet, considering the relative abundances of ecosystems, species, and genes. Species biodiversity is the level of biodiversity most commonly discussed. An estimated 1.7 million species have been scientifically documented out of a total estimated number of between 5 million and 100 million species. However, deforestation and climate change are causing such a rapid extinction of many species that some biologists are predicting the loss of 20 percent of existing species over the next 20 years. Deforestation is particularly devastating, especially in rainforests, which comprise just 6 percent of the world "e s land but contain more than 500,000 of the planet"s species. Biodiversity preservation and protection is important to humanity since diverse ecosystems provide numerous services and resources, such as protection and formation of water and soil resources; nutrient storage and cycling; pollution breakdown and absorption; food; medicinal resources; wood products; aquatic habitat; and 


\section{International Journal of Science and Research (IJSR) \\ ISSN (Online): 2319-7064 \\ Index Copernicus Value (2013): 6.14 | Impact Factor (2015): 6.391}

undoubtedly many undiscovered applications.15 Once lost, species cannot be replaced by human technology, and potential sources of new foods, medicines, and other technologies may be forever forfeited. Furthermore, degradation of ecosystems contributes to the emergence and spread of infectious diseases by interfering with natural control of disease vectors. For example, the fragmentation of North American forests has resulted in the elimination of the predators of the white-footed mouse, which is a major carrier of Lyme disease, now the leading, vector-borne infectious illness in the United States. Finally, species extinction prevents discovery of potentially useful medicines such as aspirin, morphine, vincristine, taxol, digitalis, and most antibiotics, all of which have been derived from natural sources

\section{(e) Overfishing:}

The Earth" s ocean ecosystems contain a majority of all life found on earth and other bodies of water contain over 22,000 species of fish and ocean mammals, ranging in size from the 150 ton, 40 meter long blue whale to very small fish that feed on microscopic phytoplankton. Unfortunately the world ${ }^{\text {ee }} \mathrm{s}$ fishing fleets are two to three times larger than the level that would produce a sustainable yield of fish, that is, a yield that does not deplete the stocks of fish or destroy the biodiversity of the oceans. The methods used by large commercial fishing are destructive in two ways: they result in overfishing and they decimate the ocean bottom due to the use of bottom trawling. Overfishing can be defined in terms of biological impacts or economic impacts. In an economic sense overfishing occurs when the stocks of desirable fish have been depleted to a level that makes it unprofitable for fishing companies to operate. Biologically, overfishing has occurred when the stocks of fish have become so depleted that the survival of the species is in question or the recovery of the fishery will take an extraordinarily long time. Much of the worldes human population relies on fish, both from marine capture and from aquaculture for their nutrition. In a report published by the UN Food and Agriculture Organization, the scientists reported that $52 \%$ of fish stocks are fully exploited, $17 \%$ are over-exploited, $7 \%$ are depleted, and $1 \%$ is recovering from depletion.

\section{(f) Desertification, Eutrophication, and Acidification:}

In arid and semiarid regions land degradation results in desertification, or the destruction of natural vegetative cover, which promotes desert formation. The United Nations Convention to Combat Desertification, formed in 1996 and ratified by 179 countries, reports that over 250 million people are directly affected by desertification.18 Furthermore, dry lands susceptible to desertification cover 40 percent of the Earth ${ }^{\text {ee }}$ s surface, putting at risk a further 1.1 billion people in more than 100 countries dependent on these lands for survival. China, with a rapidly growing population and economy, loses about 300,000 acres of land each year to drifting sand dunes. Two environmental conditions that frequently threaten water supplies are eutrophication and acidification. Eutrophication refers to the over-enrichment of water bodies with nutrients from agricultural and landscape fertilizer, urban runoff, sewage discharge, and eroded stream banks. Nutrient oversupply fosters algae growth, or algae blooms, which block sunlight and cause underwater grasses to die. Decomposing algae further utilize dissolved oxygen necessary for the survival of aquatic species such as fish and crabs. Eventually, decomposition in a completely oxygen less, or anoxic, water body can release toxic hydrogen sulphide, poisoning organisms and making the lake or seabed lifeless. Eutrophication has led to the degradation of numerous waterways around the world. For example, in the Baltic Sea, huge algae blooms, now common after unusually warm summers, have decreased water visibility by 10 to 15 feet in depth. Acidification is the process whereby air pollution in the form of ammonia, sulphur dioxide and nitrogen oxides, mainly released into the atmosphere by burning fossil fuels, is converted into acids. The resulting acid rain is well known for its damage to forests and lakes. Less obvious, however, is the damage caused by acid rain to freshwater and coastal ecosystems, soils, and even ancient historical monuments. The acidity of polluted rain leaches minerals from soil, causing the release of heavy metals that harm microorganisms and affect the food chain. Many species of animals, fish, and other aquatic animal and plant life are sensitive to water acidity. As a result of European directives that forced the installation of desulphurization systems and discouraged the use of coal as a fossil fuel, Europe experienced a significant decrease in acid rain in the 1990s. Nonetheless, a 1999 survey of forests in Europe found that about 25 percent of all trees had been damaged, largely due to the effects of acidification.

\section{(g) Destruction of Environmental Amenity and}

\section{Environmental Services:}

As the planet is transformed by the conversion of forests and habitat by agriculture, extraction, and development, the inherent qualities of nature that humans enjoy for recreation and in which they find wonder, peace, and relaxation, are disappearing at alarming rate. These qualities are sometimes referred to as environmental amenity and include the services of natural systems such as providing clean air and clean water. . The destruction of forests and other ecological biomes, together with human impacts on seas, oceans, lakes, rivers, and other bodies of water causes a reduction in the wide range of services provided by ecosystems. Ecosystems provide a wide range of goods and services to humankind at no cost that would otherwise be technically difficult and costly to replace. These goods and services include production of food and water; control of climate and disease; support from the major global-geochemical and nutrient cycles; crop pollination; spiritual and recreational benefits; and the maintenance of biodiversity. In a study conducted by Robert Costanza and his colleagues in 1997, they estimated the economic value of these services was estimated to be almost double global Gross Domestic Product.20 Over the past 2000 years, approximately $40-50 \%$ of Earth ${ }^{\text {ee }}$ ice-free land surface has been heavily transformed or degraded by anthropogenic activities, 66\% of marine fisheries are either overexploited or at their limit, atmospheric CO2 has increased more than $30 \%$ since the advent of industrialization, and nearly 25\% of Earth's bird species have gone extinct.21 The loss of both temperate forests and rainforests is a major component of the loss of this amenity. Rainforests, which support $60 \%$ of the world ${ }^{\text {ee }}$ s species, are disappearing at a rate of 15 million hectares per year.22 Temperate forests found mostly in the U.S., Europe, and Russia, are being destroyed at an even greater pace, with only $1 \%$ of the original U.S. and European forests remaining. 


\section{International Journal of Science and Research (IJSR) \\ ISSN (Online): 2319-7064 \\ Index Copernicus Value (2013): 6.14 | Impact Factor (2015): 6.391}

One of the outcomes of deforestation is the loss of animal habitat and unique flora and fauna which future generations will not be able to experience.

\section{(h) Poverty and the Misdistribution of Wealth:}

The Brundtland Report was the result of an effort by the United Nations to determine how to break the persistent grip of poverty on the vast majority of the world ${ }^{\text {ee }}$ s population. Poverty depends on a wide range of variables and from country to country. The poverty threshold or poverty line is generally accepted as a measure of poverty in any given country and it is defined as the minimum income required achieving an adequate standard of living in that country. The standard of living is generally accepted as the value of all resources consumed by a typical individual in one year and includes rent and transportation. Adjustments are made to the standard of living based on status (single, married, elderly), and other circumstances. In 2007, for example, the poverty threshold for a single person under 65 was $\$ 10,787$ in the United States. For a family group of four, including two children, the poverty threshold was determined to be $\$ 21,027.23$ Poverty in developed countries tends to be cyclical, that is, the number of impoverished people rises and falls with economic conditions and unemployment. In the less developed countries, poverty tends to be persistent. The terms absolute poverty and extreme poverty are sometimes used to define the form of persistent poverty which is independent of time and place. According to the United Nations, absolute poverty is "a condition characterized by severe deprivation of basic human needs, including food, safe drinking water, sanitation facilities, health shelter, education, and information. It depends not only on income but also on access to services." Absolute poverty can be defined as the absence of any two of eight basic needs:

- Food: Body Mass Index must be above 16 .

- Safe drinking water: Water must not come from solely rivers and ponds, and must be available nearby (less than a 15 minutes walk each way).

- Sanitation facilities: Toilets or latrines must be accessible in or near the home.

- $\underline{\text { Health: }}$ : Treatment must be received for serious illnesses and pregnancy.

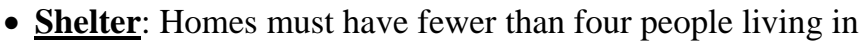
each room. Floors must not be made of dirt, mud, or clay.

- Education: Everyone must attend school or otherwise learn to read.

- Information: Everyone must have access to newspapers, radios, televisions, computers, or telephones at home.

- Access to services: Access to typical services such as education, health, legal, social, and financial (credit) services.

For the purpose of global aggregation and comparison, the World Bank uses reference lines set at \$1.25 and \$2 per day. Poverty estimates released in August 2008 showed that about 1.4 billion people in the developing world were living on less than $\$ 1.25$ a day in 2005, down from 1.9 billion in 1981 . This amounts to a reduction of absolute poverty from 1 in 4 people in 1981 to 1 in 2 people in 2008. The international poverty line of $\$ 1.25$ a day at 2005 prices is the mean of the national poverty lines for the $10-20$ poorest countries of the world. In 2001, the then 192 United Nations member states adopted the United Nations Millennium Declaration which laid out eight major development goals to be achieved by 2015. Goal 1 of the United Nation 's Millennium Development Goals is to eradicate extreme poverty and hunger. According to the World Bank, the developing world as a whole remains on track to meet the first Millennium Development Goal which is to halve extreme poverty from its 1990 levels by 2015.25 It could be said that global efforts to reduce poverty are having some success based on these statistics. However the world is entering an era of diminishing resources, including oil, metals, food, potable water and output from fisheries. The world ${ }^{\text {ees }}$ population continues to grow at a rate of about $1.7 \%$ year, straining natural and mineral resources. The result could be a reversal in these positive trends if population and consumption continue on their present trajectories.

\section{B. Analysing the Various Ethical Stand point of Sustainability:}

The Millennium Declaration-which outlines 60 goals for peace; development; the environment; human rights; the vulnerable, hungry, and poor; Africa; and the United Nations - is founded on a core set of values described as follows: "We consider certain fundamental values to be essential to international relations in the twenty-first century. These include:

- Freedom. Men and women have the right to live their lives and raise their children in dignity, free from hunger and from the fear of violence, oppression or injustice. Democratic and participatory governance based on the will of the people best assures these rights. Besides that all living species should have freedom for living in the earth occupying every things for living.

- Equality. No individual and no nation must be denied the opportunity to benefit from development. The equal rights and opportunities of women and men must be assured. Equity must be established at following manner:

i) Equity among all living species.

ii) Equity among intra-generation.

iii) Equity among inter generation

iv) Equity among sex, culture, space and time.

- Solidarity. Global challenges must be managed in a way that distributes the costs and burdens fairly in accordance with basic principles of equity and social justice. Those who suffer or who benefit least deserve help from those who benefit most.

- Tolerance. Human beings must respect one other, in all their diversity of belief, culture and language. Differences within and between societies should be neither feared nor repressed, but cherished as a precious asset of humanity. A culture of peace and dialogue among all civilizations should be actively promoted.

- Respect for nature. Prudence must be shown in the management of all living species and natural resources, in accordance with the precepts of sustainable development. Only in this way can the immeasurable riches provided to us by nature be preserved and passed on to our descendants. The current unsustainable patterns of production and consumption must be changed in the interest of our future welfare and that of our descendants.

- Shared responsibility. Responsibility for managing worldwide economic and social development, as well as threats to international peace and security, must be shared 


\section{International Journal of Science and Research (IJSR) ISSN (Online): 2319-7064 \\ Index Copernicus Value (2013): 6.14 | Impact Factor (2015): 6.391}

among the nations of the world and should be exercised multi-laterally. As the most universal and most representative organization in the world, the United Nations must play the central role." United Nations General Assembly, "United Nations Millennium Declaration," Resol.

\section{The Challenges of Environmental Ethics}

Suppose putting out natural fires, culling feral animals or destroying some individual members of overpopulated indigenous species is necessary for the protection of the integrity of a certain ecosystem. Will these actions be morally permissible or even required? Is it morally acceptable for farmers in non-industrial countries to practise slash and burn techniques to clear areas for agriculture? Consider a mining company which has performed open pit mining in some previously unspoiled area. Does the company have a moral obligation to restore the landform and surface ecology? And what is the value of a humanly restored environment compared with the originally natural environment? It is often said to be morally wrong for human beings to pollute and destroy parts of the natural environment and to consume a huge proportion of the planete's natural resources. If that is wrong, is it simply because a sustainable environment is essential to (present and future) human well-being? Or is such behaviour also wrong because the natural environment and/or its various contents have certain values in their own right so that these values ought to be respected and protected in any case? These are among the questions investigated by environmental ethics. Some of them are specific questions faced by individuals in particular circumstances, while others are more global questions faced by groups and communities. Yet others are more abstract questions concerning the value and moral standing of the natural environment and its nonhuman components.

In the literature on environmental ethics the distinction between instrumental value and intrinsic value (in the sense of "non-instrumental value") has been of considerable importance. The former is the value of things as means to further some other ends, whereas the latter is the value of things as ends in them selves regardless of whether they are also useful as means to other ends. For instance, certain fruits have instrumental value for bats who feed on them, since feeding on the fruits is a means to survival for the bats. However, it is not widely agreed that fruits have value as ends in themselves. We can likewise think of a person who teaches others as having instrumental value for those who want to acquire knowledge. Yet, in addition to any such value, it is normally said that a person, as a person, has intrinsic value, i.e., value in his or her own right independently of his or her prospects for serving the ends of others. For another example, a certain wild plant may have instrumental value because it provides the ingredients for some medicine or as an aesthetic object for human observers. But if the plant also has some value in itself independently of its prospects for furthering some other ends such as human health, or the pleasure from aesthetic experience, then the plant also has intrinsic value. Because the intrinsically valuable is that which is good as an end in itself, it is commonly agreed that somethinges possession of intrinsic value generates a prima facie direct moral duty on the part of moral agents to protect it or at least refrain from damaging it

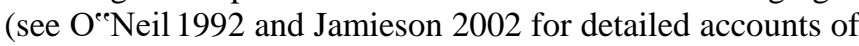
intrinsic value).

Many traditional western ethical perspectives, however, are anthropocentric or human-centered in that either they assign intrinsic value to human beings alone (i.e., what we might call anthropocentric in a strong sense) or they assign a significantly greater amount of intrinsic value to human beings than to any non-human things such that the protection or promotion of human interests or well-being at the expense of non-human things turns out to be nearly always justified (i.e., what we might call anthropocentric in a weak sense). For example, Aristotle (Politics, Bk. 1, Ch. 8) maintains that "nature has made all things specifically for the sake of man" and that the value of non-human things in nature is merely instrumental. Generally, anthropocentric positions find it problematic to articulate what is wrong with the cruel treatment of non-human animals, except to the extent that such treatment may lead to bad consequences for human beings. Immanuel Kant ("Duties to Animals and Spirits", in Lectures on Ethics), for instance, suggests that cruelty towards a dog might encourage a person to develop a character which would be desensitized to cruelty towards humans. From this standpoint, cruelty towards non-human animals would be instrumentally, rather than intrinsically, wrong. Likewise, anthropocentrism often recognizes some non-intrinsic wrongness of anthropogenic (i.e. humancaused) environmental devastation. Such destruction might damage the well-being of human beings now and in the future, since our well-being is essentially dependent on a sustainable environment (see Passmore 1974; Bookchin 1990; Norton et al. (eds.) 1995).

When environmental ethics emerged as a new sub-discipline of philosophy in the early 1970s, it did so by posing a challenge to traditional anthropocentrism. In the first place, it questioned the assumed moral superiority of human beings to members of other species on earth. In the second place, it investigated the possibility of rational arguments for assigning intrinsic value to the natural environment and its non-human contents. It should be noted, however, that some theorists working in the field see no need to develop new, non-anthropocentric theories. Instead, they advocate what may be called enlightened anthropocentrism (or, perhaps more appropriately called, prudential anthropocentrism). Briefly, this is the view that all the moral duties we have towards the environment are derived from our direct duties to its human inhabitants. The practical purpose of environmental ethics, they maintain, is to provide moral grounds for social policies aimed at protecting the earth ${ }^{\text {ee }} \mathrm{s}$ environment and remedying environmental degradation. Enlightened anthropocentrism, they argue, is sufficient for that practical purpose, and perhaps even more effective in delivering pragmatic outcomes, in terms of policy-making, than non-anthropocentric theories given the theoretical burden on the latter to provide sound arguments for its more radical view that the non-human environment has intrinsic value (cf. Norton 1991, de Shalit 1994, Light and Katz 1996). Furthermore, some prudential anthropocentrisms may hold what might be called cynical anthropocentrism, which says that we have a higher-level anthropocentric reason to be 


\section{International Journal of Science and Research (IJSR) \\ ISSN (Online): 2319-7064 \\ Index Copernicus Value (2013): 6.14 | Impact Factor (2015): 6.391}

non-anthropocentric in our day-to-day thinking. Suppose that a day-to-day non-anthropocentric tends to act more benignly towards the non-human environment on which human wellbeing depends. This would provide reason for encouraging non-anthropocentric thinking, even to those who find the idea of non-anthropocentric intrinsic value hard to swallow. In order for such a strategy to be effective one may need to hide one ${ }^{e c}$ s cynical anthropocentrism from others and even from oneself. The position can be structurally compared to some indirect form of consequentialism and may attract parallel critiques (see Henry Sidgwick on utilitarianism and esoteric morality, and Bernard Williams on indirect utilitarianism).

\section{Conclusions}

Sustainability is a meta-concept that has been applied in the creation of frameworks, such as the Natural Step, that are designed to be applied to real situations to guide citizens, organizations, government, and corporations onto a path where both present and future generations can have the potential for a good quality of life. Although it could have been merely a passing fad, sustainability has proven its staying power over the past two decades by becoming a part of the common vernacular rather than the vocabulary of specialists. National sustainability policy is not uncommon and commercial enterprises are adopting the Corporate Social Responsibility framework at an accelerating pace. At its core, sustainability is about ethics because it calls on present people to not only considering the condition of the current impoverished population, but also the potential condition of future populations who are the mercy of our production and consumption patterns. Clearly we are at a significant fork in the road, with the consequences of climate change and resource depletion on the horizon. The question of our responsibility to the future looms large and it is an ethical responsibility that should be addressed and better understood. In effect sustainability forces us to face the consequences of our behavior in a manner unlike any other concept. And as a result, developing an understanding of the ethical underpinnings of sustainability is fundamental to applying it as a solution for the many problems that are being faced or will be faced, by present and future peoples.

\section{Reference}

[1] A Sustainable Future in Our Hands - A Guide to the EU's Sustainable Development Strategy.2007.The European Commission, Brussels. Available ec.europa.eu/sustainable/docs/sds_guide_en.pdf

[2] Barbier,Edward,B.(2006),

NaturalResourcesandEconomicDevelopment.//books.go ogle.com/books?id=fYrEDAVnyUC\&pg=PA45:Cambri dgeUniversityPress.pp. 4445. 9780521706513.Retrieved April 8, 2014.

[3] Backer, E. \& John, T. (1999), Sustainability \& the Social Sciences: a- cross- disciplinary approach to integrating environmental considerations into theoretical reorientation, London \& New York: Zed Books Ltd, pp. 336.

[4] Circles of Sustainability Urban Profile Process and Scerri, Andy; James, Paul (2010). "Accounting for sustainability: Combining qualitative and quantitative research in developing =indicators " of sustainability". International Journal of Social Research Methodology 13.

[5] Costanza, R., d'Arge, R., de Groot, R., Farber, S., Grasso, M., Hannon, B., Limburg, K .Naeem, S., O'Neill, R.,Paruelo, J., Raskin, R.G., Sutton, P. \& van den Belt, M. 1997, "The value of the world's ecosystem services and natural capital" Nature, 387, pp. 253-260"

[6] FAO, Agenda 21+5, website: http://www.fao.org

[7] Fischer,T.B. (2007), Theory \& Practice of Strategic Environmental Assessment- towards a more systematic approach, Earthscan, London.

[8] Green Dot http://www.green-dot.du

[9] Jha-Thakur. U, Gazzola. P, Peel.D, Fischer.T.B, Kidd.S, (2009), Effectiveness of strategic environmental assessment- the significance of learning. Impact assessment \& project appraisal, Vol 27(2),pp. 133-144

[10] Kibert J. Charles, Thiele Leslie, Peterson A., Monroe M." The Ethics of Sustainability".

[11]Lynn R. Kahle, Eda Gurel-Atay, Eds (2014). Communicating Sustainability for the Green Economy. New York: M.E. Sharpe.ISBN 978-0-7656-3680-5.

[12]OECD 1998. Towards Sustainable Development: Environmental Indicators website:http://www.oecd.org

[13]OECD 1995. Public Management Developments, Update 1995 OECD: Paris website:http://www.oecd.org

[14] Our Common Future, 1987. The World Council on Economic Development. Oxford: Oxford University Press.

[15] Pearce, D.W., Barbier, E. D. \& Markandya, A. (1990), Sustainable Development: economics \& environment in the Third World. Chelten: Edward Elgar Publishing Limited.

[16] Pezzey, J.( 1993), Sustainable development concepts: an economic analysis (World Bank Environment Paper No. 2), Washington, DC: The World Bank.

[17] Securing the Future - The UK Government Sustainable Development Strategy. 1995. Command Paper 6467. Available www.defra.gov.uk/sustainable/government/publications/ uk-strategy/index.htm

[18] Sharachchandra Lélé. 1991. "Sustainable Development: A Critical Review", World Development 19(6), pp. 607621.

[19] "Sustainable development | Define Sustainable development at Dictionary.com". Retrieved 2016-01-09.

[20] United Nations (2014). Prototype Global Sustainable Development Report (Online unedited ed.). New York: United Nations Department of Economic and Social Affairs, Division for Sustainable Development.

[21] UNWTO/UNEP, (2005), "Policies and Tools for Sustainable Tourism - -AGuide for Policy makers"

[22] Upham, Paul, 2000, "An assessment of The Natural Step theory of sustainability" Journal of Cleaner Production, 8, pp. 445-454. 